\title{
Hydrogen peroxide-mediated oxidative stress induces inflammasome activation in term human placental explants
}

\author{
Priscila Rezeck Nunes $^{\mathrm{a}, *}$, Maria Terezinha Serrao Peracoli ${ }^{\mathrm{b}}$, Mariana Romao-Veiga ${ }^{\mathrm{b}}$, \\ Mariana Leticia Matias ${ }^{\mathrm{a}}$, Vanessa Rocha Ribeiro ${ }^{\mathrm{a}}$, Celio Junior Da Costa Fernandes ${ }^{\mathrm{b}}$, \\ Jose Carlos Peracoli ${ }^{a}$, Jose Ricardo Rodrigues ${ }^{a}$, Leandro De Oliveira ${ }^{a}$ \\ a Department of Gynaecology and Obstetrics, Medical School, Botucatu Sao Paulo State University (Unesp), 18618-970 Sao Paulo, Brazil \\ ${ }^{\mathrm{b}}$ Department of Microbiology and Immunology, Institute of Biosciences, Botucatu Sao Paulo State University (Unesp), 18618-691 Sao Paulo, Brazil
}

A R T I C L E I N F O

\section{Keywords:}

Oxidative stress

Inflammasome

Cytokines

Placental explants

\begin{abstract}
A B S T R A C T
Background: The placenta is a multifunctional organ that can suffer with imbalances between pro- and antioxidant molecules, contributing for inflammatory imbalance. The inflammation generated by oxidative stress may induce inflammasome activation, an essential complex for pro-inflammatory cytokine production. Objective: The aim of this study was to evaluate whether hydrogen peroxide $\left(\mathrm{H}_{2} \mathrm{O}_{2}\right)$ mediated oxidative stress induces inflammasome activation on placental explants.

Study design: Tissue cultures of placental explants obtained from normotensive pregnant women were performed in different concentrations of $\mathrm{H}_{2} \mathrm{O}_{2}$. Gene expressions of NLRP3, caspase-1, IL-1 $\beta$, TNF- $\alpha$ and IL-10 were evaluated by qPCR. Superoxide dismutase (SOD), catalase, Heat shock protein 70 (Hsp70), Caspase-1, TNF- $\alpha$, IL-1 $\beta$, IL-10 and human Chorionic Gonadotropin (hCG) were determined by ELISA.

Results: Concentrations of catalase, Hsp70, hCG and SOD were higher in cultures with 100 and $1000 \mu \mathrm{M} \mathrm{H}_{2} \mathrm{O}_{2}$ compared to controls. Gene and protein expressions of TNF- $\alpha$ and IL- $1 \beta$ were elevated in cultures with $1000 \mu \mathrm{M}$ $\mathrm{H}_{2} \mathrm{O}_{2}$ compared to controls. This concentration led to inflammasome activation, by increasing gene expressions of NLRP3, caspase-1 and IL-1 $\beta$. In contrast, gene and protein expressions of IL-10 were reduced at 100 and $1000 \mu \mathrm{M} \mathrm{H}_{2} \mathrm{O}_{2}$. Protein expression of caspase- 1 was higher in cultures of $100 \mu \mathrm{M} \mathrm{H}_{2} \mathrm{O}_{2}$ compared to controls. Treatment with Glybenclamide at $200 \mu \mathrm{M}$ was used to prevent NLRP3 inflammasome activation. This concentration reduced protein expression of caspase- 1 compared to culture with only $\mathrm{H}_{2} \mathrm{O}_{2}$ and control cultures. Conclusions: Our results confirm that $\mathrm{H}_{2} \mathrm{O}_{2}$ induces oxidative stress on placental explants and demonstrate that cell responses to this stress involve inflammasome activation.
\end{abstract}

\section{Introduction}

The formation of reactive oxygen species (ROS), known as prooxidant factors, is a characteristic of aerobic cellular metabolism. However, the production of pro-oxidant factors must be balanced by antioxidant factors to maintain cellular homeostasis. The imbalance between pro- and antioxidant factors in favor to pro-oxidant products constitutes the oxidative stress [1]. This imbalance leads to lipid peroxidation, cellular modifications and damages, alters protein production and the DNA structure [2].

In spite of the pathological processes related to oxidative stress, it is also possible to recognize its presence in physiological conditions. It has been demonstrated that pregnancy is highly marked by oxidative metabolism due to the progressive increase in oxygen demand in either maternal or fetal compartments. This increase in demand has the consequence of greater formation of ROS. However, the balance between pro- and antioxidant factors in healthy pregnancies prevents the exacerbation of oxidative stress [3].

Placental development is highly orchestrated in order to maintain its initial formation in a hypoxic condition until 10-12 gestational weeks [4]. Burton et al. reported a real blockage of the maternal spiral arterioles by trophoblasts at eight weeks of pregnancy. It is supposed that this mechanical process prevents the release of excessive $\mathrm{O}_{2}{ }^{-}$radicals at the maternal-fetal interface and protects the placental tissue during these early stages of differentiation [5]. This blockage performed by trophoblasts is gradually dissipated between 10 and 12 gestational weeks, allowing progressive increase in oxygen tension at the maternal-fetal interface. Interestingly, this increase in oxygen tension is

\footnotetext{
* Corresponding author at: Department of Gynaecology and Obstetrics, São Paulo State University (Unesp), Medical School, Botucatu, 18618-970 São Paulo, Brazil.

E-mail addresses: priscilarezeck@gmail.com, priscilarezeck@alunos.fmb.unesp.br (P.R. Nunes).
} 
coincident with an increase in the antioxidant properties of the syncytiotrophoblast $[5,6]$.

Alterations in trophoblast functions in consequence of the imbalance between pro- and antioxidant properties may lead to placenta related disorders, like preeclampsia. This is a multifactorial disease marked by breaking of immunological tolerance, abnormalities in the uterine circulatory development and oxidative stress. Clinical manifestations of preeclampsia result from intense systemic inflammatory response and endothelial dysfunction [4-7].

Conditions of cellular stress or injury also activate the inflammasomes, multiprotein complexes that recognize several endogenous stimuli considered as danger signals [8]. Inflammasome complexes are able to activate caspase- 1 and consequently trigger maturation of pro$\mathrm{IL}-1 \beta$ and pro-IL-18 into $\mathrm{IL}-1 \beta$ and $\mathrm{IL}-18$, respectively. IL- $1 \beta$ is a proinflammatory mediator in many immune reactions, whereas mature IL-18 is important for the production of interferon- $\gamma$ and potentiation of cytolytic activity of natural killer cells and T cells. Inflammasome formation requires a pattern recognition receptor (PRR) as the sensor. Five PRRs have been described: NLRP1, NLRP3, NLRC4, Pyrin and AIM2. Among these PRRs, NLRP3 inflammasome is the most versatile complex and oxidative stress has been described as a trigger for its activation [9-11].

The different ligands and the exact mechanisms of Nod-like receptor 3 (NLRP3) activation are still unclear. What is known is that danger signals, such as uric acid and cholesterol crystals, free radicals derived from oxygen and fatty acids can induce NLRP3 inflammasome activation, playing important roles on diseases involving inflammatory responses [8-10].

Formation of this multiprotein complex requires activation of caspase-1, present in the cytosol as an inactive zymogen: procaspase-1 [12]. After activation of inflammasome, caspase-1 is also necessary for the release of some cytokines, such as IL-1 $\beta$ [13]. It is not clear whether the biological functions of caspase- 1 are restricted to the cytosol. Caspase-1 may mediate the spread of inflammation from cell to cell, in the extracellular environment or through circulation. Caspase-1 and IL-1 $\beta$ are secreted out of the cells as a signal of NLRP3 inflammassome activation, which may contribute to the inflammatory state [14].

Recently, we showed that monocytes from women with preeclampsia present increased basal gene expressions of NLRP1 and NLRP3 receptors, suggesting the involvement of these PRRs in the pathophysiology of the disease [15]. We also demonstrated that preeclamptic placentas show higher expression of NLRP3 inflammasome, which may be involved in the exaggerated inflammatory state seen in this disease [16]. Xu et al. also suggested that NLRP3 may be involved in the development of preeclampsia in a Chinese Han population [17].

Other studies have also contributed to the current knowledge on inflammasome activation in placental disorders [18,19]. All these suggestions prompted us to investigate whether oxidative stress, a mechanism associated with these placental disorders, is able to induce inflammasomes in placenta.

\section{Material and methods}

\subsection{Study population and ethics statement}

This study consisted of 15 healthy pregnant women with normal evolution of the pregnancy, with no personal history of hypertensive disorders in pregnancy. These pregnant women were admitted to the Obstetrics Unit of Botucatu Medical School, Sao Paulo State University, Botucatu, SP, Brazil between November 2015 and May 2016. Gestational age was calculated from the last menstrual period and confirmed by ultrasound dating. Exclusion criteria included chronic hypertension, multiple gestation, prior preeclampsia, illicit drug use, and preexisting medical conditions such as diabetes, cancer, acute infectious disease, cardiovascular, autoimmune, renal and hepatic diseases. The study was approved by the Ethics Committee of the Botucatu
Medical School, and written informed consent was obtained from all women involved in the study (CAAE Protocol number: 37160614500005411). In addition, we inform that all experiments were performed in accordance with relevant guidelines and regulations.

\subsection{Collection of placental tissue}

Placentas were collected from 15 normal pregnant women delivered by elective cesarean section. Immediately after delivery, all placentas considered for the study were examined macroscopically and processed within $10 \mathrm{~min}$. Fragments of approximately $5 \times 5 \mathrm{~cm}$ were immediately removed from the central region of the placenta, constituting samples in contact with the maternal side (basal plate). After this initial collection, smaller fragments were washed in buffered saline (PBS) and separated from the decidual layer that is normally adhered to the basal plate. The terminal portions of the villi were evidenced in PBS (the villi were seen floating freely in the liquid) and dissected in small sections to constitute explants.

\subsection{Cell viability assay}

Explant viability was verified by the release of the intracelular enzyme lactate dehydrogenase (LDH) into the incubation medium after $24,48,72$ and $96 \mathrm{~h}$ of incubation. The same investigation was performed to verify the explant viability under treatment with 10, 100 and $1000 \mu \mathrm{M} \mathrm{H}_{2} \mathrm{O}_{2}$ during $24 \mathrm{~h}$. LDH concentrations were determined with a Lactate Dehydrogenase Assay kit (Sigma-Aldrich, St Louis, MO, USA), according to the manufacturer's protocol.

\subsection{Culture of placental explants with hydrogen peroxide}

A total of $11 \mathrm{mg}$ of human villous tissue was cultured in RPMI 1640 culture medium supplemented with $2 \mathrm{mM}$ L-glutamine (Sigma-Aldrich), $40 \mathrm{mg} / \mathrm{ml}$ antibiotic/antimycotic (Sigma-Aldrich) and 10\% fetal bovine serum (Gibco BRL Life Technologies, The Netherlands) in a 24-well plates (SPL Life Sciences, Korea) during $24 \mathrm{~h}$ for stabilization [20]. After stabilization placental explants were treated with hydrogen peroxide in the following concentrations: 10, 100 or $1000 \mu \mathrm{M} \mathrm{H} \mathrm{H}_{2} \mathrm{O}_{2}$ for $4 \mathrm{~h}$ and $24 \mathrm{~h}$. All experiments were performed in duplicate.

\subsection{Inhibitory assay}

Explant cultures in the presence of Glybenclamide at $200 \mu \mathrm{M}$ (Sigma-Aldrich) were performed in order to block inflammasome activation. Lamkanfi et al. showed that Glybenclamide prevented activation of the NLRP3 inflammasome, being the first drug identified to inhibit this activation by danger signals and IL-1 $\beta$ secretion [21]. The drug was added to cultures $30 \mathrm{~min}$ before the addition of hydrogen peroxide (at $100 \mu \mathrm{M}$ ).

\subsection{Oxidative stress markers}

Superoxide dismutase (SOD) and catalase activity were measured in placental explant culture supernatants after $4 \mathrm{~h}$ of incubation using commercial kits (Cayman Chemical Company, USA). Heat shock protein 70 (Hsp70) and human Chorionic Gonadotropin (hCG) were measured in culture supernatants after $24 \mathrm{~h}$ of incubation using commercial kits (R\&D Systems, Minneapolis, MN, USA for Hsp70 and Sigma-Aldrich for hCG). The sensitivity limits of the kits for each marker are: SOD: $0.005 \mathrm{U} / \mathrm{mL}$; Catalase: $2 \mathrm{nmol} / \mathrm{min} / \mathrm{mL}$; Hsp70: $125 \mathrm{pg} / \mathrm{mL}$; hCG: $50 \mathrm{pg} / \mathrm{mL}$.

\subsection{Gene expression in placental explants}

Placental explants were evaluated for the expression of the genes encoding IL-1 $\beta$, IL-10 and TNF- $\alpha$ proteins at the transcriptional level. In 
Table 1

Primers for inflammasome genes, cytokines and GAPDH.

\begin{tabular}{|c|c|c|c|}
\hline Gene & Sequence $\left(5^{\prime}-3^{\prime}\right)$ & Name & GeneBank \\
\hline Caspase-1 & $\begin{array}{l}\text { Forward primer: (1065)AGACATCCCACAATGGGCTC(1084) } \\
\text { Reverse primer: (1172)TGAAAATCGAACCTTGCGGAAA(1151) }\end{array}$ & CASP1 & NM_033292.3 \\
\hline NLRP3 & $\begin{array}{l}\text { Forward primer: (2826)GAGGAAAAGGAAGGCCGACA(2845) } \\
\text { Reverse primer: (2917)TGGCTGTTCACCAATCCATGA(2897) }\end{array}$ & NLRP3 & NM_004895.4 \\
\hline$\underline{\text { IL-1 } \beta}$ & $\begin{array}{l}\text { Forward primer: (544)GAGCAACAAGTGGTGTTCTCC(564) } \\
\text { Reverse primer: (653)AACACGCAGGACAGGTACAG(634) }\end{array}$ & IL1B & NM_000576.2 \\
\hline$\underline{\text { TNF- }} \alpha$ & $\begin{array}{l}\text { Forward primer: (325)GCTGCACTTTGGAGTGATCG(344) } \\
\text { Reverse primer: (462)GGGTTTGCTACAACATGGGC(443) }\end{array}$ & TNF & NM_000594.3 \\
\hline$\underline{\text { IL-10 }}$ & $\begin{array}{l}\text { Forward primer: (361)AAGACCCAGACATCAAGGCG(380) } \\
\text { Reverse primer: (445)ATTCGATGACAGCGCCGTAG(426) }\end{array}$ & IL10 & NM_000572.2 \\
\hline GAPDH & $\begin{array}{l}\text { Forward primer: (684)CGTGGAAGGACTCATGACCA(703) } \\
\text { Reverse primer: (801)GGCAGGGATGATGTTCTGGA(782) }\end{array}$ & GAPDH & NM_002046.4 \\
\hline
\end{tabular}

addition, gene expressions of the inflammasome were evaluated through NLRP3 and caspase-1 genes.

Total RNA was extracted from the placental explants after culture using the Total RNA Purification Kit (Norgen Biotek Corp., Thorold, Canada) according to the manufacturer's protocol, and the Reverse Transcription-coupled polymerase chain reaction (RT-qPCR) was performed as described previously [15]. Briefly, isolated RNA was DNAse I Amp Grade (Invitrogen) treated. Subsequently, the synthesis of complementary DNA (cDNA) was conducted using ImProm-II ${ }^{\mathrm{TM}}$ Reverse Transcription System, according to manufacturer's protocol. The RTqPCR was performed using RT GoTaq-qPCR Master Mix (Promega, Madison, WI, USA) and the primer sequences used in this study are listed in Table 1. Each reaction was set in duplicate and the conditions for the RT-qPCR were as follows: initial denaturation at $96^{\circ} \mathrm{C}$ for $2 \mathrm{~min}$ and then 40 cycles at $95^{\circ} \mathrm{C}$ for $15 \mathrm{~s}$ and $60{ }^{\circ} \mathrm{C}$ for $60 \mathrm{~s}$, followed by a melting curve. Expression values of the analyzed transcripts were normalized to that of the enzyme-encoding glyceraldehyde-3-phosphate dehydrogenase gene (GAPDH). The calculation of the differential expression of selected genes was carried out by the data processing method compared with a standard curve [22]. To analyze the relative expression, after the analysis of gene expression, we chose an RNA sample obtained from each group, which received the relative value of 100. All other samples received values for that sample.

\subsection{Cytokine and caspase-1 determination}

Concentrations of TNF- $\alpha$, IL- $1 \beta$, IL-10 and caspase- 1 in culture supernatants of placental explants were determined by enzyme-linked immunosorbent assay (ELISA), using Quantikine ELISA kits (R\&D
Systems) according to the manufacturer's instructions. Concentrations of caspase-1 in culture supernatants with or without $100 \mu \mathrm{M}$ of $\mathrm{H}_{2} \mathrm{O}_{2}$ and in cultures treated with Glybenclamide at $200 \mu \mathrm{M}$ were also determined. Assay sensitivity limits of the kits are: $1.6 \mathrm{pg} / \mathrm{mL}$ for TNF- $\alpha$, $3.9 \mathrm{pg} / \mathrm{mL}$ for IL- $1 \beta$ and IL-10 and $0.68 \mathrm{pg} / \mathrm{mL}$ for caspase- 1 .

\subsection{Statistical analysis}

Data were analyzed using the statistical program PRISM (Graph Prism for Windows, version 6.01, GraphPad, USA) and are presented as means \pm SD. Differences among groups were tested using one-way ANOVA, followed by post-hoc Tukey test. A $P$ value less than 0.05 was considered to be statistically significant.

\section{Results}

\subsection{Cell viability was preserved in $24 \mathrm{~h}$ culture and balanced among} different concentrations of $\mathrm{H}_{2} \mathrm{O}_{2}$

To determine the effects of an oxidant microenvironment on inflammasome activation, human placental explants from third trimester of pregnancy were treated with or without different concentrations of $\mathrm{H}_{2} \mathrm{O}_{2}$. Results of $\mathrm{LDH}$ enzyme determination in the supernatants from these cultures are shown in Fig. 1. Placental explants cultured for $24 \mathrm{~h}$ presented satisfactory viability with the lowest level of LDH (20.85 \pm 3.28) (Fig. 1A) and therefore this time of culture was used for the entire experiment. Analysis of LDH release at $24 \mathrm{~h}$-culture with different concentrations of $\mathrm{H}_{2} \mathrm{O}_{2}(10,100$ and $1000 \mu \mathrm{M})$ did not show significant differences among treatments (Fig. 1B).

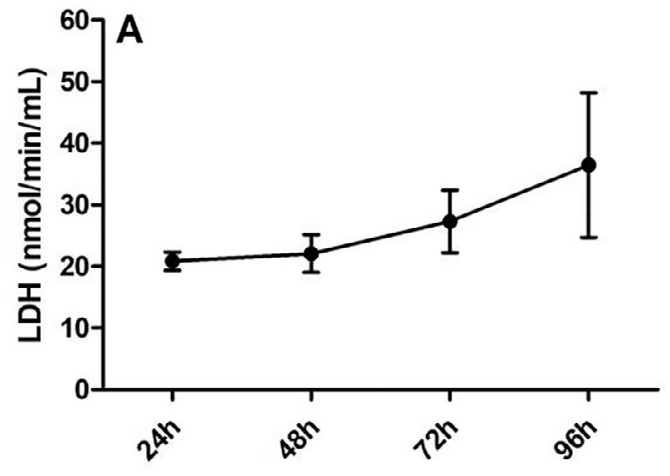

Time of culture

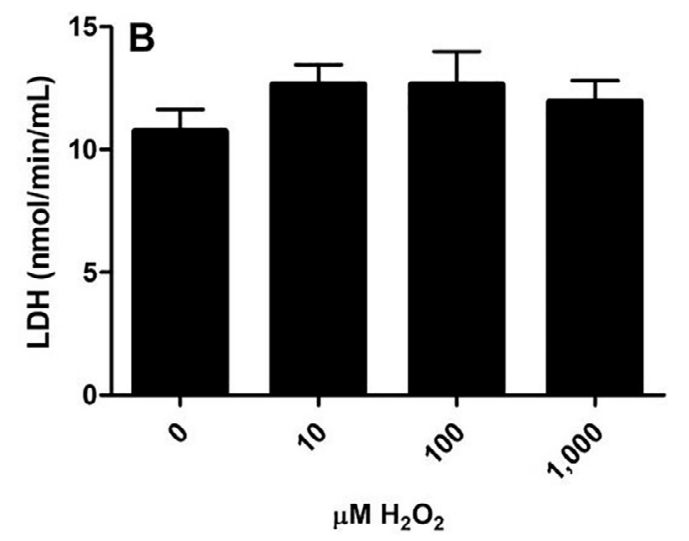

Fig. 1. Cell viability of placental explants. Concentration of lactate dehydrogenase (LDH) detected in supernatant of placental explants cultured during $24,48,72$ and $96 \mathrm{~h}$ (A). Concentrations of $\mathrm{LDH}$ in $24 \mathrm{~h}$ cultures in absence or presence of 10,100 , and $1000 \mu \mathrm{M} \mathrm{H}_{2} \mathrm{O}_{2}$ (B). Data are presented as mean \pm SD. (ANOVA). 

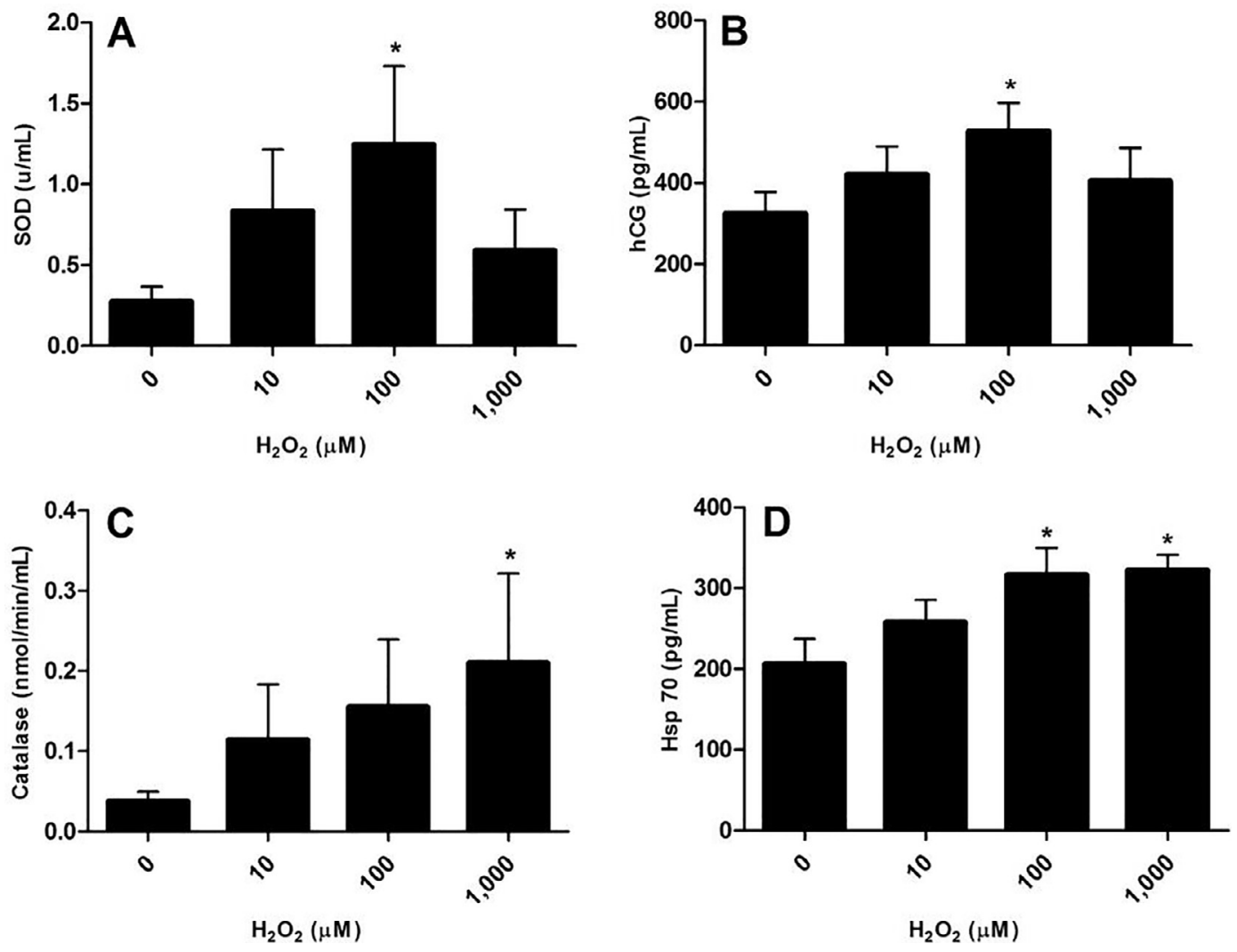

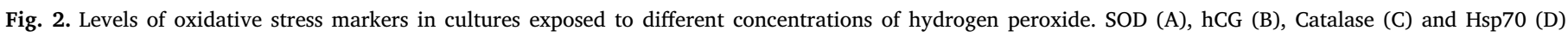
concentrations detected in supernatants of placental explant cultures. Results expressed as mean \pm SD. ${ }^{*}(P<0.05)$ vs. 0 (ANOVA).

\subsection{Oxidative stress markers were higher in concentration of 100 and $1000 \mu \mathrm{M} \mathrm{H}_{2} \mathrm{O}_{2}$}

The treatment of placental explants with $\mathrm{H}_{2} \mathrm{O}_{2}$ led to changes in the concentrations of superoxide dismutase (SOD), human chorionic gonadotrophin (hCG), catalase and heat shock protein 70 (Hsp70) measured in the supernatants. Fig. 2 shows the concentrations of all these markers. The highest levels of SOD $(1,16 \pm 0,34)$, hCG $(528,40 \pm 68,91)$ and Hsp70 $(316 \pm 33,40)$ were found in cultures treated with $100 \mu \mathrm{M} \mathrm{H} \mathrm{H}_{2} \mathrm{O}_{2}$ and the highest levels of catalase $(0,24 \pm 0,090)$ were detected in cultures exposed to $1000 \mu \mathrm{M} \mathrm{H}_{2} \mathrm{O}_{2}$, with statistical difference $(P<0.05)$ when compared to control without treatment with $\mathrm{H}_{2} \mathrm{O}_{2}$.

\subsection{Oxidative stress generated by $\mathrm{H}_{2} \mathrm{O}_{2}$ induced activation of} inflammasome NLRP3 and the treatment with Glybenclamide inhibited gene expression of NLRP3, IL-1 $\beta$ and caspase-1

Gene expression of NLRP3 $(139,10 \pm 25,13)$ (Fig. 3A) was higher in culture of placental explants treated with $100 \mu \mathrm{M} \mathrm{H} \mathrm{H}_{2} \mathrm{O}_{2}$, while caspase-1 $(117,90 \pm 21,24)$ (Fig. 3B) and IL-1ß $(162,30 \pm 34,04)$ gene expression (Fig. 3C) were higher in cultures with $1000 \mu \mathrm{M} \mathrm{H}_{2} \mathrm{O}_{2}$ compared to control cultures. The same was seen regarding protein expression of IL-1 $\beta(271,60 \pm 44,69)$ (Fig. 3D). All these results presented statistical significance $(P<0.05)$ and suggest inflammasome activation under oxidative stress. The pre-treatment of placental explants with Glybenclamide at $200 \mu \mathrm{M}$ significantly $(P<0.05)$ inhibited gene expression of NLRP3 $(150,40 \pm 13,75)$ (Fig. 4A) and IL$1 \beta(232,70 \pm 31,32)$ (Fig. 4B) in the same way as protein expression of caspase-1 (226 \pm 37,07) (Fig. 4C) compared to control cultures and cultures treated only with $\mathrm{H}_{2} \mathrm{O}_{2}$, confirming the activation of this inflammasome pathway.

\subsection{Pro- and anti-inflammatory cytokine profile showed a balance to reduce inflammation}

Gene $(167,60 \pm 47,8)$ and protein $(40,64 \pm 3,06)$ expressions of TNF- $\alpha$ were higher in placental explants cultured with 100 and $1000 \mu \mathrm{M} \mathrm{H} \mathrm{H}_{2} \mathrm{O}_{2}$ (Fig. 5A and 5B) when compared to controls $(P<0.05)$.

The results regarding gene $(2326 \pm 668,80)$ and protein $(45,52 \pm 2,76)$ expressions of IL-10, demonstrated in Fig. 5C and 5D, showed a decrease in the protein expression of this cytokine under treatments with 100 and $1000 \mu \mathrm{M} \mathrm{H}_{2} \mathrm{O}_{2}$, with significant difference $(P<0.05)$ compared to cultures without treatment with $\mathrm{H}_{2} \mathrm{O}_{2}$.

\section{Discussion}

The present study evaluated the effect of oxidative stress induced by $\mathrm{H}_{2} \mathrm{O}_{2}$ on the occurrence of inflammasome activation in placental explants of pregnant women at term (39-40 weeks), without clinical or obstetric disorders identified and undergone to elective cesarean section. The methodology applied to this work intended to reproduce experimentally the pathophysiology of obstetric complications related to placental dysfunction caused by uterine circulatory alterations. These alterations are responsible for the establishment of the hypoxia-reoxygenation phenomenon and consequent production of ROS. Among obstetric complications related to this pathophysiology, preeclampsia, with or without associated fetal growth restriction, is undoubtedly the most studied. Our group has demonstrated the involved of NLRP3 inflammasome in preeclampsia $[15,16]$.

The results of LDH release obtained from supernatants of placental explants cultured during different times and exposed to different concentrations of $\mathrm{H}_{2} \mathrm{O}_{2}$ supported the methodology used, allowing the identification of $24 \mathrm{~h}$ as the best culture time to be employed for determination of oxidative markers and gene and protein expressions 

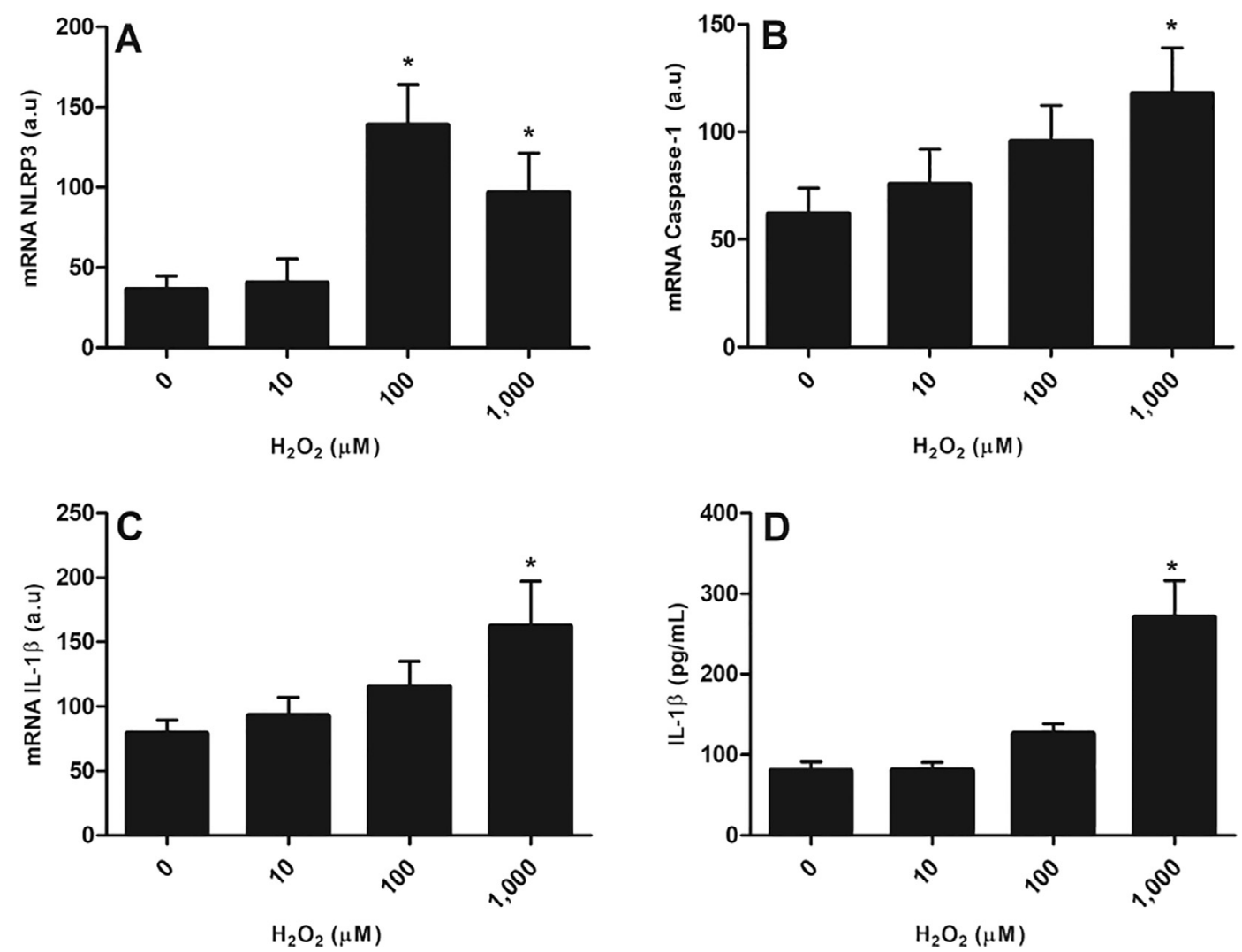

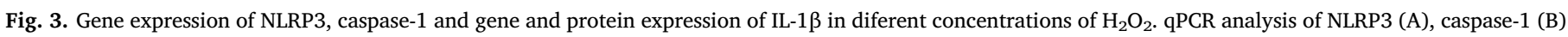

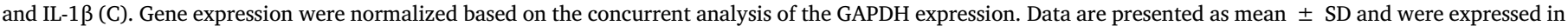
arbitrary units (a.u). Protein expression of IL-1 $\beta$ (D) expressed in pg/mL. * $(P<0.05)$ vs. $0,10 \mu \mathrm{M} \mathrm{H} \mathrm{H}_{2} \mathrm{O}_{2}$ (ANOVA).

related to inflammasome activation. Greater LDH gene expression and increased activity of this enzyme have been demonstrated in preeclamptic placentas [23]. Thus, the activity of this enzyme has been considered as a possible marker in some pregnancy complications related to placental alterations. Increased LDH were demonstrated in placental tissues submitted to hypoxia-reoxygenation and these findings suggest a link between oxidative stress and cell death by apoptosis [24].

In our study, the production of SOD and hCG showed similar patterns. They presented the highest concentrations in the cultures treated with $100 \mu \mathrm{M} \mathrm{H}_{2} \mathrm{O}_{2}$, and reduced values in cultures with $1000 \mu \mathrm{M} \mathrm{H}_{2} \mathrm{O}_{2}$. These results may be explained by a limitation in the cellular capacity of antioxidant productions in response to the oxidative stress. Decreased levels of SOD have been associated with complications in pregnancy, and the reduction of SOD activity has been demonstrated in preeclamptic placentas [25]. Interestingly, supplementations with antioxidant components before or during pregnancy have not been shown to be effective in preventing complications related to oxidative stress, which raises the importance of evaluating the intrinsic capacity of antioxidant production by tissues involved in these complications, such as placental tissues [26,27].

Autocrine/paracrine regulation and syncytiotrophoblast turnover are influenced by the balance between oxidative action and placental antioxidative capacity. The secretion of hCG, which is considered as a marker of syncytiotrophoblast function is modulated in vitro by oxygen tension and ROS [28-30]. Kharfi et al. reported positive correlation between hCG and $\mathrm{H}_{2} \mathrm{O}_{2}$ in the maternal circulation suggesting an association between oxidative stress and hCG secretion [31]. Another study showed that hCG levels were proportional to $\mathrm{H}_{2} \mathrm{O}_{2}$ concentrations up to $50 \mu \mathrm{M}$. After this concentration, there was a decrease in hCG production [32]. Our results corroborate with these authors, since hCG production by placental explants reached the maximum in cultures treated with $100 \mu \mathrm{M} \mathrm{H}_{2} \mathrm{O}_{2}$, with a decrease in the levels of this hormone in supernatants of explants treated with $1000 \mu \mathrm{M} \mathrm{H}_{2} \mathrm{O}_{2}$.

In our experiments, the high levels of catalase produced by explants treated with $\mathrm{H}_{2} \mathrm{O}_{2}$ may be responsible for cell viability maintenance against deleterious effects caused by the oxidative stress. However, the application of this hypothesis in clinical practice is still inconsistent, as some authors have demonstrated a decrease in catalase activity in pregnancies complicated by preeclampsia, while others have supported an increase in the activity of this enzyme [33-35].

The activity of Hsp70 was similar to catalase, reaching higher activity in the concentrations of 100 and $1000 \mu \mathrm{M} \mathrm{H} \mathrm{H}_{2} \mathrm{O}_{2}$. Since Hsp70 works in cellular recovery from stress and against injury, this protein is also considered as a marker of oxidative stress [36,37]. It has been detected at high circulating levels in preeclampsia [38,39].

Recent data has provided connections between inflammation and oxidative stress capable of propagating the inflammatory response [40]. These findings have highlighted the role of ROS in the regulation of NLRP3 inflammasome [41].

In the present study, the oxidative stress induced by $\mathrm{H}_{2} \mathrm{O}_{2}$ on placental explants contributed to the inflammatory profile generated by activating NLRP3 inflammasome, caspase- 1 and inducing the release of IL-1 $\beta$. The production of IL- $1 \beta$ is associated with tissue damage and inflammation, and inflammatory activation may be related to these factors [42].

We demonstrated that gene expressions of NLRP3, caspase-1 and IL$1 \beta$ have similar patterns, with greater expression in cultures treated with the concentration of 100 and $1000 \mu \mathrm{M} \mathrm{H}_{2} \mathrm{O}_{2}$ and are blocked after glybenclamide pre-treatment. These results point to the activation of the inflammasome complex as a consequence of a common form of cellular stress initiated by different stimuli, such as the release of ROS $[43,44]$. In addition, the protein expression of caspase- 1 was higher in the $100 \mu \mathrm{M} \mathrm{H}_{2} \mathrm{O}_{2}$ treated culture, compared to the control culture and the culture treated with glybenclamide. This result agrees with the gene 

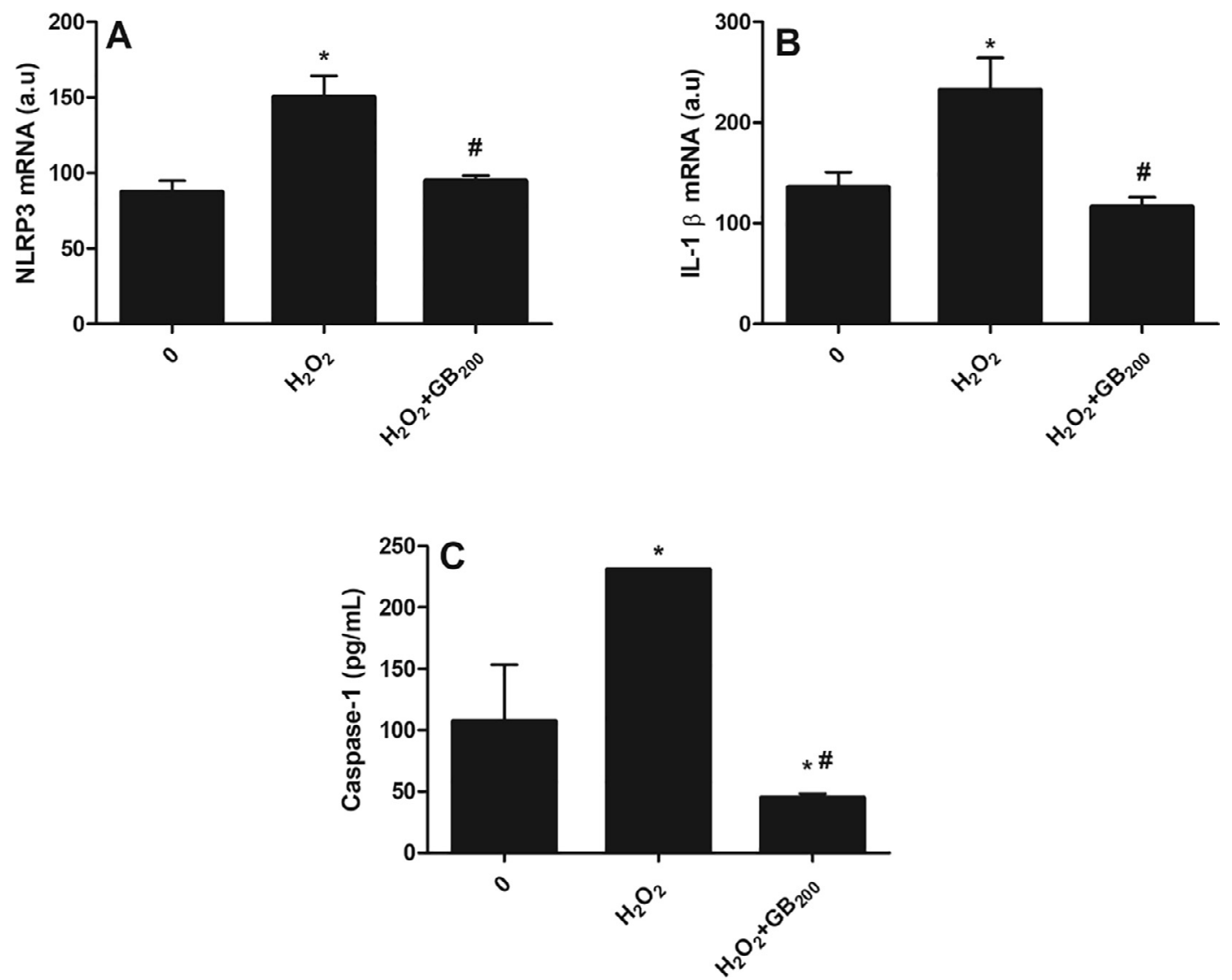

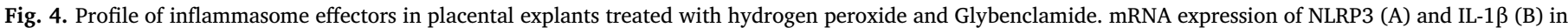

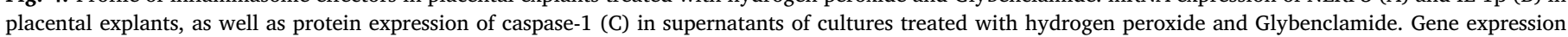

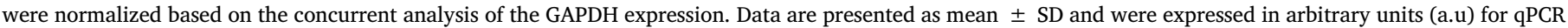
analysis and $\mathrm{pg} / \mathrm{mL}$ for caspase- 1 analysis. ${ }^{*}(P<0.05)$ vs. 0 ; \# $(P<0.05)$ vs. $\mathrm{H}_{2} \mathrm{O}_{2}$ (ANOVA).

expression of caspase-1, which participates in the activation of inflammassome during the oxidative stress state. When inflammasome is blocked by the addition of glybenclamide, the protein expression of caspase-1 decreases significantly in the supernatant.

Our results confirm previous studies of caspase- 1 maturation and externalization in active form after inflammasome formation and its blockage after treatment with inflammasome inhibition [45-48].

Gene expressions and protein levels of TNF- $\alpha$ and IL- $1 \beta$ were significantly higher when placental explants were treated with 100 and $1000 \mu \mathrm{M} \mathrm{H}_{2} \mathrm{O}_{2}$ compared to control cultures. The lower gene expression and production of these inflammatory cytokines observed in lower concentrations of $\mathrm{H}_{2} \mathrm{O}_{2}$ could be due to the regulation exerted by IL-10 on these cells. The predominance of IL-10 in normal pregnancies affects the regulation of the inflammatory response that occurs in pregnancy by controlling the gene expressions of IL-1 $\beta$ and TNF- $\alpha$. It is known that IL-10 exerts an inhibitory effect on the production of inflammatory cytokines, such as IL-1 $\beta$ and TNF- $\alpha$ [49]. In the present study lower gene and protein expressions of IL-10 in placental explants cultured with higher concentrations of $\mathrm{H}_{2} \mathrm{O}_{2}$ might suggest an increase in the inflammatory response mediated by oxidative stress induced by $\mathrm{H}_{2} \mathrm{O}_{2}$ measured in the supernatants. Corroborating with this hypothesis, the explants cultured in the absence of $\mathrm{H}_{2} \mathrm{O}_{2}$ showed higher IL-10 gene and protein expression. Oxidative stress, caused by high concentrations of $\mathrm{H}_{2} \mathrm{O}_{2}$, seems to be able to decrease the levels of IL-10, probably due to the cytokine production imbalance caused by the inflammatory state generated in this condition [50].

\section{Conclusions}

Taken together, the results of the present study confirm that $\mathrm{H}_{2} \mathrm{O}_{2}$ induces oxidative stress in placental explants, demonstrated by activation of NLRP3 inflammasome, increased production of inflammatory cytokines and antioxidant agents in order to control the inflammatory state. Activation of inflammasome are an essential element of the innate immune system and disorders in these processes have been implicated in various inflammatory and infectious diseases [44]. It has been postulated that oxidative stress may also contribute to placental tissue senescence and to the pathophysiology of various placental related disorders, such as preeclampsia and fetal growth restriction [51]. Thus, initiatives to reduce stress on trophoblastic tissue should be considered for future researches. In this sense, the use of natural products with antioxidant and anti-inflammatory effects still need to be evaluated in order to reduce oxidative stress and decrease the activation of inflammasome in placental tissue.

\section{Disclosure of conflict of interest}

None.

\section{Funding}

This work was supported by the Fundação de Amparo a Pesquisa do Estado de São Paulo, FAPESP (Grant No 2014/25611-5). 

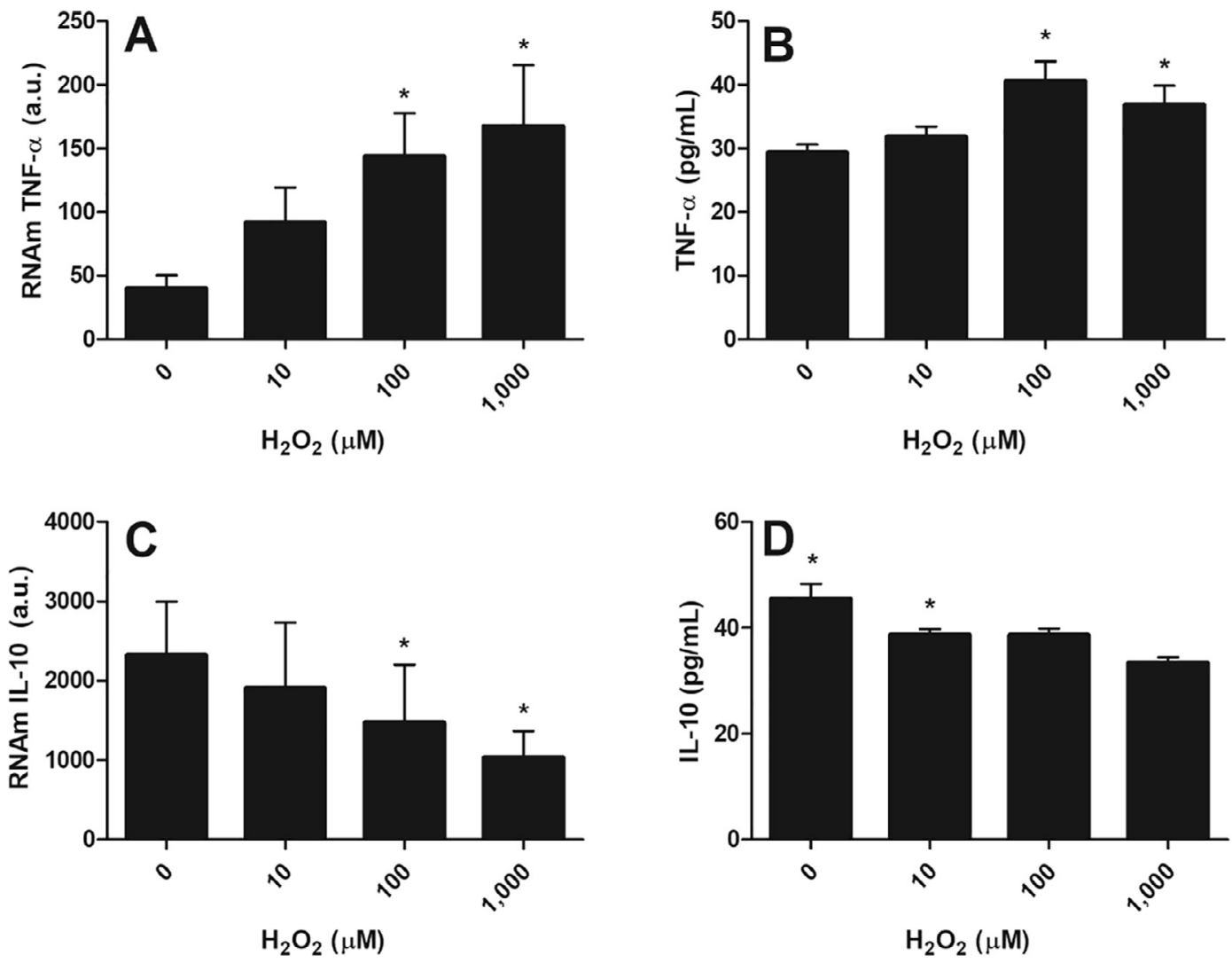

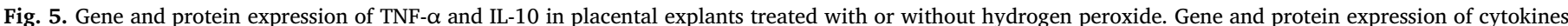

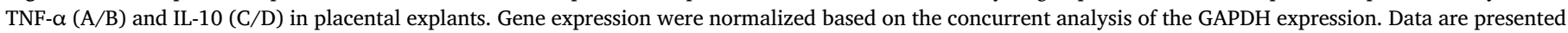
as mean \pm SD and were expressed in arbitrary units (a.u) for qPCR analysis or pg/mL for ELISA analysis. * $(P<0.05)$ vs. 0 (ANOVA).

\section{Author contributions}

M.T.P., L.D.O. and P.R.N. conceived and designed the experiments, P.R.N., M.R.V., M.L.M., V.R.R. and C.J.C.F. performed the experiments, P.R.N., M.T.P., M.R.V. and L.D.O. analyzed the data, P.R.N., L.D.O. and M.R.V. contributed reagents/materials/analysis tools, P.R.N., L.D.O. and M.T.P. wrote the paper, J.R.R., J.C.P and L.D.O. selected pregnant women.

\section{Appendix A. Supplementary data}

Supplementary data associated with this article can be found, in the online version, at https://doi.org/10.1016/j.preghy.2018.07.006.

\section{References}

[1] H. Sies, Oxidative stress: from basic research to clinical application, Am. J. Med. 91 (1991) 31-38.

[2] B. Kalyanaraman, Teaching the basics of redox biology to medical and graduate students: oxidants, antioxidants and disease mechanisms, Redox Biol. 1 (2013) 244-257.

[3] G. Kaur, S. Mishra, A. Sehgal, R. Prasad, Alterations in lipidperoxidation and antioxidant status in pregnancy with preeclampsia, Mol. Cell. Biochem. 313 (2008) $37-44$.

[4] K. Red-Horse, Y. Zhou, O. Genbacev, A. Prakobphol, R. Foulk, M. McMaster, S.J. Fisher, Trophoblast differentiation during embryo implantation and formation of the maternal-fetal interface, J. Clin. Invest. 114 (2004) 744-754.

[5] G.J. Burton, E. Jauniaux, A.L. Watson, Maternal arterial connections to the placental intervillous space during the first trimester of human pregnancy: the Boyd collection revisited, Am. J. Obstet. Gynecol. 181 (1999) 718-724.

[6] E. Jauniaux, A.L. Watson, J. Hempstock, Y.P. Bao, J.N. Skepper, G.J. Burton, Onset of maternal arterial bloodflow and placental oxidative stress: a possible factor in human early pregnancy failure, Am. J. Pathol. 157 (2003) 251-3262.

[7] T. Matsubara, Y. Matsubara, A. Nawa, Nitric oxide and reactive oxygen species in the pathogenesis of preeclampsia, Int. J. Mol. Sci. 16 (2015) 4600-4614.

[8] C.S. Yang, D.M. Shin, E.K. Jo, The role of NLR-related protein 3 inflammasome in host defense and inflammatory diseases, Int. Neurourol. J. 16 (2012) 2-12.

[9] T. Strowig, J. Henao-Mejia, E. Elinav, R. Flavell, Inflammasomes in health and disease, Nature 481 (2012) 278-286.

[10] K. Schroder, J. Tschopp, The inflammasomes, Cell 140 (2010) 821-832.

[11] Y. He, H. Hara, G. Núñez, Mechanism and regulation of NLRP3 inflammasome activation, Trends Biochem. Sci. 41 (12) (2016) 1012-1021.

[12] M. Lamkanfi, V. Dixit, The inflammasomes, PloS Pathog. 5 (12) (2009) e1000510, https://doi.org/10.1371/journal.ppat.1000510 Epub 2009 Dec 24.

[13] G. Lopez-Castejon, D. Brough, Understanding the mechanism of IL-1ß secretion, Cytokine Growth Factor Rev. 4 (2011) 189-195.

[14] L. Wang, H. Fu, G. Nanayakkara, Y. Li, Y. Shao, C. Johnson, J. Cheng, W.Y. Yang, F. Yang, M. Lavallee, Y. Xu, X. Cheng, H. Xi, J. Yi, J. Yu, E.T. Choi, H. Wang, $\mathrm{X}$. Yang, Novel, extracellular and nuclear caspase-1 and inflammasomes propagate inflammation and regulate gene expression: a comprehensive database mining study, J. Hematol. Oncol. 9 (2016) 122.

[15] M.L. Matias, M. Romão, I.C. Weel, V.R. Ribeiro, P.R. Nunes, V.T. Borges, J.P. Araújo Jr., J.C. Peraçoli, L. de Oliveira, M.T. Peraçoli, Endogenous and uric acid-induced activation of NLRP3 inflammasome in pregnant women with preeclampsia, PLoS One 10 (2015) e0129095.

[16] I.C. Weel, M. Romão-Veiga, M.L. Matias, E.G. Fioratti, J.C. Peraçoli, V.T. Borges, J.P. Araujo Jr., M.T. Peraçoli, Increased expression of NLRP3 inflammasome in placentas from pregnant women with severe preeclampsia, J. Reprod. Immunol. 123 (2017) 40-47.

[17] L. Xu, S. Li, Z. Liu, S. Jiang, J. Wang, M. Guo, X. Zhao, W. Song, S. Liu, The NLRP3 rs10754558 polymorphism is a risk factor for preeclampsia in a Chinese Han population, J. Matern. Fetal Neonatal Med. 31 (2018) 1-8.

[18] S. Kohli, Maternal extracellular vesicles and platelets promote preeclampsia via inflammasome activation in trophoblasts, Blood 27 (2016) 2153-2164.

[19] K. Tamura, G. Ishikawa, M. Yoshie, W. Ohneda, A. Nakai, T. Takeshita, E. Tachikawa, Glibenclamide inhibits NLRP3 inflammasome-mediated IL-1 $\beta$ secretion in human trophoblasts, J. Pharmacol. Sci. 135 (2017) 89-95.

[20] J. Yu, L. Feng, Y. Hu, Y. Zhou, Effects of SAC on oxidative stress and NO availability in placenta: potential benefits to preeclampsia, Placenta 33 (2012) 487-494.

[21] M. Lamkanfi, J.L. Mueller, A.C. Vitari, S. Misaghi, A. Fedorova, K. Deshayes, W.P. Lee, H.M. Hoffman, V.M. Dixit, Glyburide inhibits the Cryopyrin/Nalp3 inflammasome, J. Cell Biol. 5 (2009) 61-70.

[22] A. Larionov, A. Krause, W. Miller, A standard curve based method for relative real time PCR data processing, BMC Bioinf. 21 (2005) 6.

[23] S.C. Tsoi, J. Zheng, F. Xu, H.H. Kay, Differential expression of lactate dehydrogenase isozymes (LDH) in human placenta with high expression of LDH-A(4) isozyme in the endothelial cells of pre-eclampsia villi, Placenta 22 (2001) 317-322. 
[24] M.L. Tjoa, T. Cindrova-Davies, O. Spasic-Boskovic, D.W. Bianchi, G.J. Burton, Trophoblastic oxidative stress and the release of cell-free feto-placental DNA, Am. J. Pathol. 169 (2006) 400-404.

[25] J. Vanderlelie, K. Venardos, V.L. Clifton, N.M. Gude, F.M. Clarke, A.V. Perkins, Increased biological oxidation and reduced anti-oxidant enzyme activity in preeclamptic placentae, Placenta 26 (2005) 53-58.

[26] K. Duhig, L.C. Chappell, A.H. Shennan, Oxidative stress in pregnancy and reproduction, Obstet. Med. 9 (2016) 113-116.

[27] F. Wu, F.J. Tian, Y. Lin, Oxidative stress in placenta: health and diseases, Biomed Res. Int. 2015 (2015) 293271, , https://doi.org/10.1155/2015/293271.

[28] E. Alsat, P. Wyplosz, A. Malassiné, Hypoxia impairs cell fusion and fusion and differentiation process in human cytotrophoblast in vitro, J. Cell. Physiol. 168 (1996) 346-353.

[29] M.S. Weedon-Fekjær, K. Taskén, Spatiotemporal dynamics of hCG/cAMP signaling and regulation of placental function, Placenta 33 (2011) 87-91.

[30] P.P. Díaz, C.P. Sibley, S.L. Greenwood, Oxygen-sensitive K + channels modulate human chorionic gonadotropin secretion from human placental trophoblast, PLoS One 11 (2016) e014902110.1371/journal.pone.0149021.

[31] A. Kharfi, Y. Giguère, P. De Grandpré, J.M. Moutquin, J.C. Forest, Human chorionic gonadotropin (hCG) may be a marker of systemic oxidative stress in normotensive and preeclamptic term pregnancies, Clin. Biochem. 38 (2005) 717-721.

[32] A. Kharfi-Aris, S. Leblanc, A. Ouellet, J.M. Moutquin, Dual action of $\mathrm{H}_{2} \mathrm{O}_{2}$ on placental hCG secretion: implications for oxidative stress in preeclampsia, Clin. Biochem. 40 (2006) 94-97.

[33] J.T. Gohil, P.K. Patel, P. Gupta, Evaluation of oxidative stress and antioxidant de fence in subjects of preeclampsia, J. Obstet. Gynaecol. India 61 (2012) 638-640.

[34] J.Y. Yan, X. Xu, Relationships between concentrations of free fatty acid in serum and oxidative-damage levels in placental mitochondria and preeclampsia, Zhonghua Fu Chan Ke Za Zhi 47 (2012) 412-417.

[35] H. Wiktor, M. Kankofer, Catalase activity in normal and preeclamptic placentas, Ginekol. Pol. 72 (2001) 1228-1232.

[36] G. Birnbaum, Stress proteins: their role in the normal central nervous system and in disease states, especially multiple sclerosis, Springer Semin. Immunopathol. 17 (1995) 107-118.

[37] F. Barut, A. Barut, B. Dogan Gun, Expression of heat shock protein 70 and endothelial nitric oxide synthase in placental tissue of preeclamptic and intrauterine growth-restricted pregnancies, Pathol. Res. Pract. 206 (2010) 651-656.

[38] C.W. Redman, D.S. Tannetta, R.A. Dragovic, C. Gardiner, J.H. Southcombe,
G.P. Collett, I.L. Sargent, Does size matter? Placental debris and the pathophysiology of pre-eclampsia, Placenta Supplement A, Trophoblast Res. 2 (2010) 48-54.

[39] J.C. Peraçoli, C.F. Bannwart-Castro, M. Romao, I.C. Weel, V.R. Ribeiro, V.T. Borges, M.V. Rudge, S.S. Witkin, M.T. Peraçoli, High levels of heat shock protein 70 are associated with pro-inflammatory cytokines and may differentiate early- from lateonset preeclampsia, J. Reprod. Immunol. 100 (2) (2013) 129-134.

[40] J. Lugrin, N. Rosenblatt-Velin, R. Parapanov, L. Liaudet, The role of oxidative stress during inflammatory processes, Biol. Chem. 395 (2014) 203-230.

[41] M. Haneklaus, L.A. O'Neill, R.C. Coll, Modulatory mechanisms controlling the NLRP3 inflammasome in inflammation: recent developments, Curr. Opin. Immunol. 25 (2013) 40-45.

[42] M. Lamkanfi, V.M. Dixit, Inflammasomes and their roles in health and disease, Annu. Rev. Cell Dev. Biol. 28 (2012) 137-161.

[43] F. Martinon, Signaling by ROS drives inflammasome activation, Eur. J. Immunol. 40 (2010) 616-619.

[44] M. Lamkanfi, L.V. Walle, T.D. Kanneganti, Deregulated inflammasome signaling in disease, Immunol. Rev. 243 (2011) 163-173.

[45] A. Baroja-Mazo, F. Martín-Sánchez, A. Gomez, The NLRP3 inflammasome is released as a particulate danger signal that amplifies the inflammatory response, Nat. Immunol. 15 (8) (2014) 738-748.

[46] R. Laliberte, J. Eggler, G. Gabel, ATP treatment of human monocytes promotes caspase-1 maturation and externalization, J. Biol. Chem. 274 (52) (1999) 36944-36951.

[47] O. Huet, R.J. Pickering, C. Tikellis, C. Latouche, F. Long, B. Kingwell, B. Dickinson, C.J. Chang, S. Masters, F. Mackay, M.E. Cooper, J.B. de Haan, Protective effect of inflammasome activation by hydrogen peroxide in a mouse model of septic shock, Crit. Care Med. 45 (2) (2017) e184-e194.

[48] O.R. Shamaa, S. Mitra, M.A. Gavrilin, M.D. Wewers, Monocyte caspase-1 is released in a stable, active high molecular weight complex distinct from the unstable cell lysate-activated caspase-1, PLoS One 24 (2015) 10(11):e0142203.

[49] K.W. Moore, M.R. Malefity, R.L. Coffman, A. O'Garra, Interleukin-10 and the interleukin-10 receptor, Annu. Rev. Immunol. 19 (2001) 683-765.

[50] A.C. Harmon, D.C. Cornelius, L.M. Amaral, The role of inflammation in the pathology of preeclampsia, Clin. Sci. 130 (2016) 409-419.

[51] G.J. Burton, H.W. Yung, A.J. Murray, Mitochondrial-endoplasmic reticulum interactions in the trophoblast: stress and senescence, Placenta (2016) 4.001, 10.1016/ placenta. 